\title{
Neonatal Gastric Perforation with Peritonitis- A Rare Case Report
}

\author{
Patel VK ${ }^{1}$, Gaharwar APS ${ }^{2}$, Shrivastava $\mathbf{N}^{3}$, Patel $\mathbf{U}^{4}$, Grower $\mathbf{J}^{5}$ \\ ${ }^{1}$ Dr. Vishnu Kumar Patel, Assistant Professor, Department of Surgery, SS Medical College, Rewa, MP, ${ }^{2}$ Dr. APS Gaharwar, \\ Professor Department of Surgery, SS Medical College, Rewa, MP, ${ }^{3}$ Dr. Neelesh Shrivastava, PG Student, Department of \\ Surgery, SS Medical College, Rewa, MP, ${ }^{4}$ Dr. Umesh Patel, Associate Professor, Department of Pediatrics, LN Medical \\ College, Bhopal, MP, ${ }^{5}$ Dr. Jitendra Grower, Assistant Professor, Pediatric Surgery, LN Medical College, Bhopal, MP, India
}

Address for Correspondence : Dr. Vishnu Kumar Patel, drvishnupatel@gmail.com

\begin{abstract}
Gastric perforation in neonate is a very rare, serious and life threatening clinical condition. Most of the time etiology is unknown but associated with high mortality. We hereby present a case of 10 days old female with gastric perforation, which successfully managed surgically.
\end{abstract}

\section{Introduction}

Gastric perforation in neonates is a rare, serious and life threatening problem, which has very high mortality rate. Till date less than 200 cases were reported in medical literature. A high index of suspicion is essential for an early diagnosis, but because of very low incidence, it is not considered, as a common differential diagnosis of acute abdomen in this age group. Acute gastric surgical conditions in neonates are relatively few in number and most of the time etiology is uncertain [1][2]. Management depends on the extent of perforation, timing of detection and associate complications like peritonitis, pneumoperitoneum, obstruction and associated metabolic derangements etc. However, in recent years, advancement of life support system, development of pediatrics surgery as a subspecialty along with development of very effective antibiotic, have improved outcome in perforation peritonitis. We present a rare case, a 10 day's old female who present with progressive abdominal distention and pneumo-peritoneum following the gastric perforation.

\section{Case Report}

A 10 days old female baby weighing $3.1 \mathrm{~kg}$, delivered at term, normal vaginally at hospital, was admitted in emergency surgical department with excessive crying, poor activity, feed intolerance, progressive distension of abdomen, difficulty in breathing and not passing stool since last 3 days. No history of previous hospitalization and any drug (including NSAID or steroids) intake. On examination she was sick looking. Vital parameters were unstable with pulse rate $180 / \mathrm{min}$, respiratory rate $65 / \mathrm{min}$, she was febrile with axillary temperature $38^{\circ} \mathrm{C}$. On abdominal examination there was distention, abdominal tenderness (cry on palpation) and absent bowel sound. Abdominal X-ray shows significant amount of gas under the right dome of diaphragm (Figure 1).

First, abdomen was decompressed with nasogastric tube. Then other supportive steps to maintain temperature, hydration, electrolyte, blood sugar, urine output etc were taken. Preoperative antibiotics were started. Despite all resuscitative measures, there was progressive abdominal distension. Intra-peritoneal drainage by inserting Ryle's tube $(14 \mathrm{~F})$ in to abdominal cavity was done. Slightly yellowish colored fluid (about 300ml) drained from abdomen with large amount of gas. After 24 hours of intra-peritoneal drainage, an emergency laparotomy was performed. A perforation injury of one fourth size of the posterior gastric wall of stomach was found. There was no active serosal ulceration or active arterial bleeding seen. Repair was done in two layers. Post operative course was uneventful and patient was discharged without any sequelae.

Manuscript received: $7^{\text {th }}$ Jan 2015

Reviewed: $17^{\text {th }}$ Jan 2015

Author Corrected: $19^{\text {th }}$ Jan 2015

Accepted for Publication: $13^{\text {th }}$ Feb 2015 


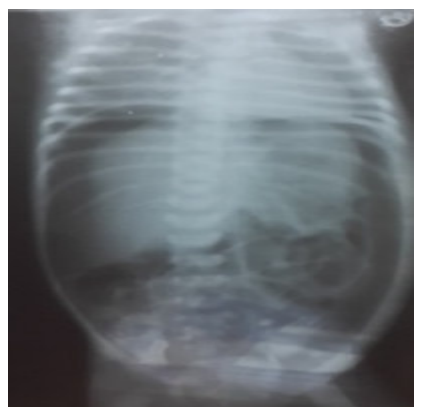

Fig 1: Abdominal x-ray (erect) showing free air under the diaphragm

\section{Discussion}

Gastric perforation in the newborn infant was first described by Siebold in 1825 [5]. Many theories have been proposed for the pathogenesis of gastric perforation, but in most of cases, etiology is still unknown. In known cases, iatrogenic trauma by vigorous nasogastric or orogastric tube placement is common [6]. There is lot of other factors including prematurity, vigorous resuscitation, nasal CPAP, perinatal stress, perinatal hypoxia-ischemia, and distal obstruction, have been suggested for spontaneous perforation [3][4]. Ischemic gastric perforations have been noted in conjunction with necrotizing enterocolitis. Spontaneous gastric perforation as earlier is more common in preterm baby, most commonly reported in otherwise healthy neonate, between $2^{\text {nd }}$ and $7^{\text {th }}$ day. Maximum reported incidence of rupture is on $3^{\text {rd }}$ day of life [7]. Postnatal steroid therapy is reported for gastro-duodenal perforation [8].

Our baby was full term and the perforation was occurs on $3^{\text {rd }}$ day of life. Sudden abdominal distension has been reported as predominant symptoms. The most common radiographic finding of gastric perforation is pneumoperitoneum which was seen in our cases. Mostly the perforation have been seen on greater curvature and measured between $0.5 \mathrm{~cm}$ to $8 \mathrm{~cm}$. In our case perforation was $2 \mathrm{~cm}$ in size, located on the posterior wall of stomach. Prompt surgical intervention with debridement and two layers closure of gastric tear are recommended management and delay in surgery will result in higher mortality. Postoperative vigorous supportive therapy along with broad spectrum intravenous antibiotics is necessary. In very sick infants, short-term external peritoneal drainage, like in our case, may be required, followed by surgical repair of the perforation once the infant's condition stabilized [8][9]. Due to the associated problems of sepsis and respiratory failure, often found in premature infants, mortality rates of gastric perforation are high, ranging from $45 \%$ to $58 \%$ [10]. For better

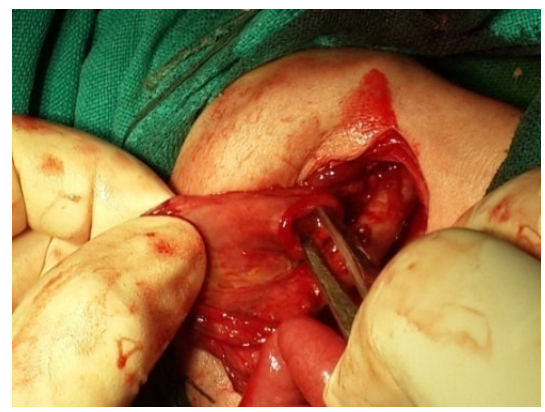

Case Report

Fig 2: Large gastric perforation in the posterior wall of the stomach

outcome, interval between starting of symptom and definitive surgical intervention should be minimum.

\section{Conclusion}

Any new born child having progressive abdominal distension and pneumo-peritoneum, diagnosis of gastric perforation should be kept in mind and early resuscitation and surgical exploration is to be undertaken for better outcome.

\section{Funding: Nil}

Conflict of interest: Nil

Permission from IRB: Yes

\section{References}

1. Lin CM, Lee HC, Kao HA, Hung HY, Hsu CH, Yeung CY, Sheu JC, Wang NL. Neonatal gastric perforation: Report of 15 cases and review of literature. Pediatr Neonatol. 2008 Jun;49(3):65-70.

2. Teruik K, Iwai J, Yamada S, Takenouchi A, Nakata M, Komatsu S, Yoshida H. Etiology of neonatal gastric perforation: A review of 20 year's experience. Pediatr Surg Int. 2012 Jan;28(1):9-14.

3. Leone RJ, Krasna IH. "Spontaneous" gastric perforation: is it really spontaneous? J Pediatr Surg 2000 July;35(7):1066-9.

4. Gunaydin M, Rizalar R, Bozkurter AT, Tander B, Ariturk E, Bernay F. Gastric serosal tear due to congenital pyloric atresia: A rare anomaly, a rare complication. Afr J Pediatr Surg 2011;8(2):232-4.

5. Durham EC, Goldenstein RM. Rupture of the stomach in newborn infants. J Pediatr 1934;4:44 
6. Grosfeld JL, Molinari F, Chaet M, Engum SA, West $\mathrm{KW}$, Rescorla FJ, et al. Gastrointestinal perforation and peritonitis in infants and children: Experience with 179 cases over ten years. Surgery 1996;120:650-6

7. Ryckman FC. Selected anomalies and intestinal obstruction. In: Avery A, Fanarof AA, Richard J, Martin RJ, editors. Neonatal perinatal medicine diseases of the fetus and infant. $7^{\text {th }}$ ed. USA: Mosby; 2002. p. 1283.

8. Stark AR, Carlo WA, Tyson JE, Paile LA, Wright LL, Shankaran S, et al. Adverse Effects of Early
Dexamethasone Treatment in Extremely-Low-BirthWeight Infants. N Engl J Med 2001;344:95-101.

9. Kshirsagar AY, Vasisth GO, Ahire MD, Kanojiya RK, Sulhyan SR. Acute spontaneous gastric perforation in neonates: A report of three cases. Afr J Paediatr Surg 2011;8:79-8.

10. Rosser SB, Clark CH, Elechi EN. Spontaneous neonatal gastric perforation. J Pediatr Surg 1982;17:3904.

\section{How to cite this article?}

Patel VK, Gaharwar APS, Shrivastava N, Patel U, Grower J. Neonatal Gastric Perforation with Peritonitis- A Rare Case Report. Pediatr Rev: Int J Pediatr Res 2014;1(3):80-82. doi: 10.17511/ijpr.2014.i03.03 